\author{
V. Salini \\ D. De Amicis \\ G. Guerra \\ T. Iarussi \\ R. Sacco \\ C.A. Orso
}

\title{
Osteochondroma of the scapula: a case report
}

Received: 28 September 2006

Accepted: 21 January 2007

Published online: 5 March 2007

\author{
V. Salini $(\bowtie)$ • D. De Amicis • G. Guerra \\ C.A. Orso \\ Department of Orthopaedics \\ and Traumatology \\ SS. Maria Annunziata Hospital \\ University G. D’Annunzio \\ Via Dei Vestini, Chieti, Italy \\ E-mail: v.salini@unich.it \\ T. Iarussi • R. Sacco \\ Department of Thoracic Surgery \\ SS. Maria Annunziata Hospital \\ Chieti, Italy
}

\begin{abstract}
Osteochondroma is one of the most common benign tumors of the axial skeleton. Location of a solitary exostosis in the scapula is relatively rare. We report the case of an osteochondroma of the scapula in a 13-year-old boy. Because of the atypical location with nonspecific shoulder pain, the diagnosis is often made late. CT is necessary to determine the correct position of the osteochondroma. Despite the young age of the patient, surgical excision of the exostosis was performed, because of an arising thoracic pressure pain. The outcome was good, the patient noticed disap-
\end{abstract}

pearance of previous painful symptoms, and a normal profile of the scapula was gained.

Key words Osteochondroma • Shoulder pain $\cdot$ Thoracic pressure pain

\section{Introduction}

Osteochondroma, or single exostosis, is one of the most common benign tumors of the axial skeleton. It is a hamartoma that originates from the subperiosteal exuberant cartilage and that, while growing produces bone with characteristics similar to those of the endochondral skeleton $[1,2]$. Osteochondroma constitutes $20 \%-50 \%$ of all benign bone tumors and $10 \%-15 \%$ of all bone tumors $[3,4]$. It is mainly located at the metaphysis of the long bones (35\% of cases affect the knees, while the hips, ribs, spinal column, hands and feet are rarely affected) $[5$, 6]. Exostosis in the scapula is relatively rare: about $8.5 \%$ of cases [2].

Pain and dysfunction often accompany this anatomic derangement [7]. These lesions are radiopaque and easily identified with computed tomography (CT). Due to their distinct borders, these lesions can easily be followed radiographically with CT as well as plain radiography. CT is necessary to determine the precise location of the neoformation and its relationship with the surrounding soft tissues, to enable accurate surgical removal which is the only adequate treatment.

At the Orthopaedic and Trauma Clinic of G. D'Annunzio University of Chieti, we observed a case of osteochondroma that was interesting from both the radiographic and clinical points of view, and that was treated successfully.

\section{Case report}

A 13-year-old boy was admitted to hospital with a neoformation on the left scapula. The growth had been initially discovered 6 years before and over time grew in volume.

Radiographic and CT exam revealed an alteration in the bone structure of a mixed type, with radiographic 

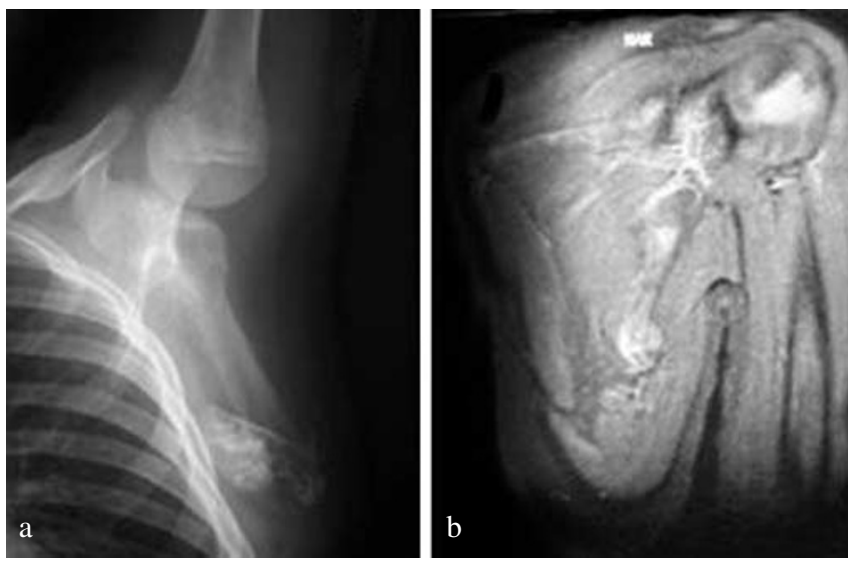

Fig. 1a, b Exostosis of the inferior angle of the scapula in a 13year-old boy. a Radiograph. b Computed tomogram

characteristics of exostosis, at the inferior angle of the left scapula (Fig. 1).

Clinically, the swelling was of round appearance with a diameter of about $4 \mathrm{~cm}$. It was painful when pressed, was linked to the underlying bone structure and was of such a large size as to change the profile of the medial scapula, which was higher than the contralateral one. The articular elasticity of the shoulder was limited to medium stages with antalgic arrest and it was possible, through auscultation and palpation, to hear and feel joint grinding and clicking movements when moving the joint to different positions.

Preventive treatment with antibiotics was undertaken before and after surgery. Surgery was performed under general anaesthesia. The patient was placed in lateral position (Fig. 2). Through a muscle-sparing rear miniarthrotomy, after isolating the lower part of the scapula, the exostosis, situated in the front of the scapula was first isolated and then resected.

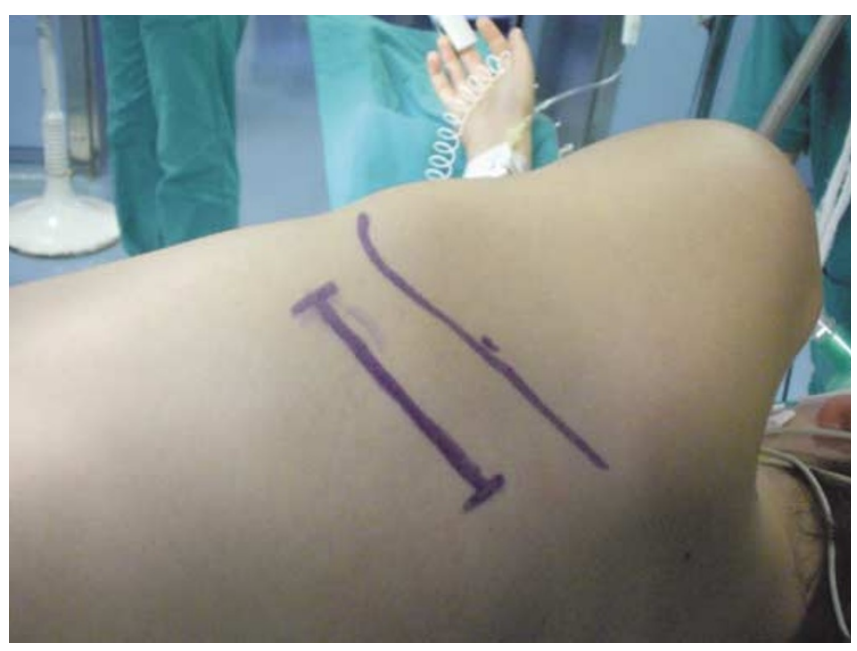

Fig. 2 The lateral position under surgery
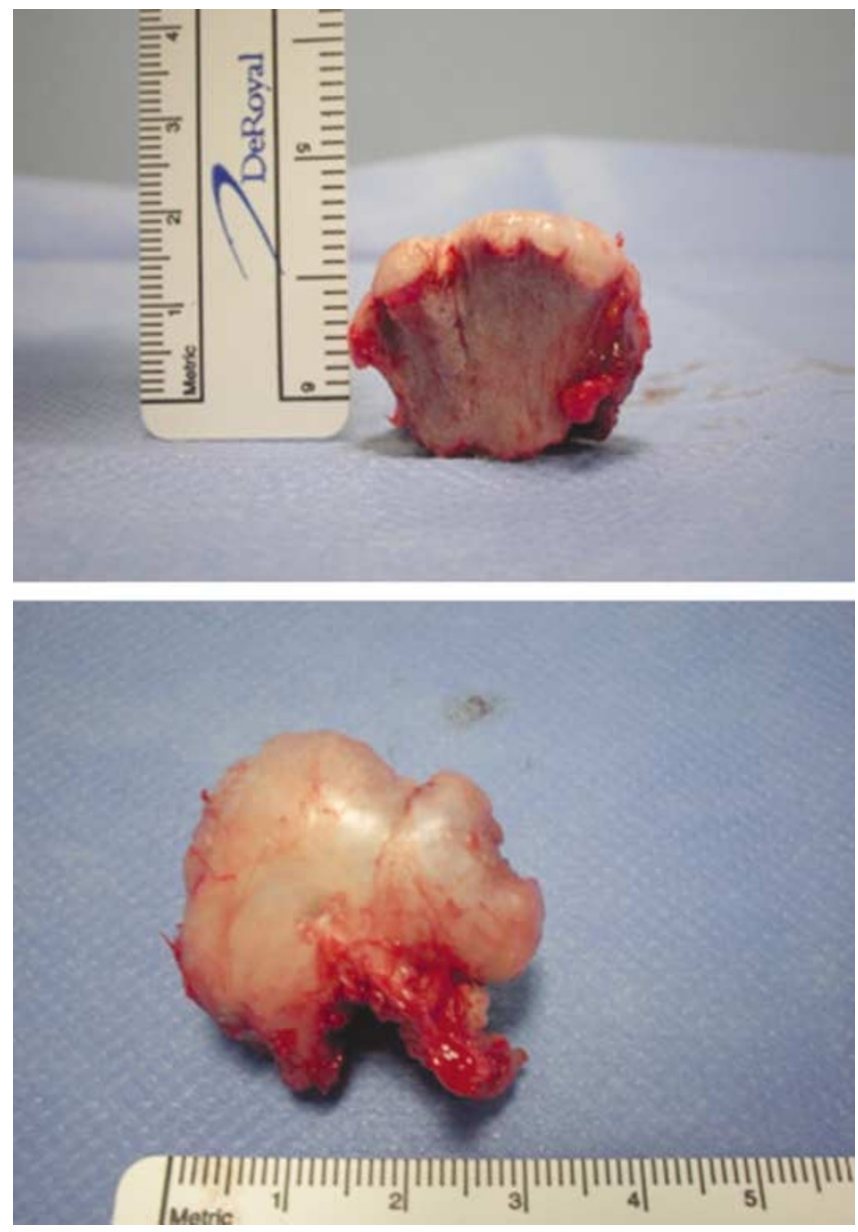

Fig. 3 The exostosis once resected

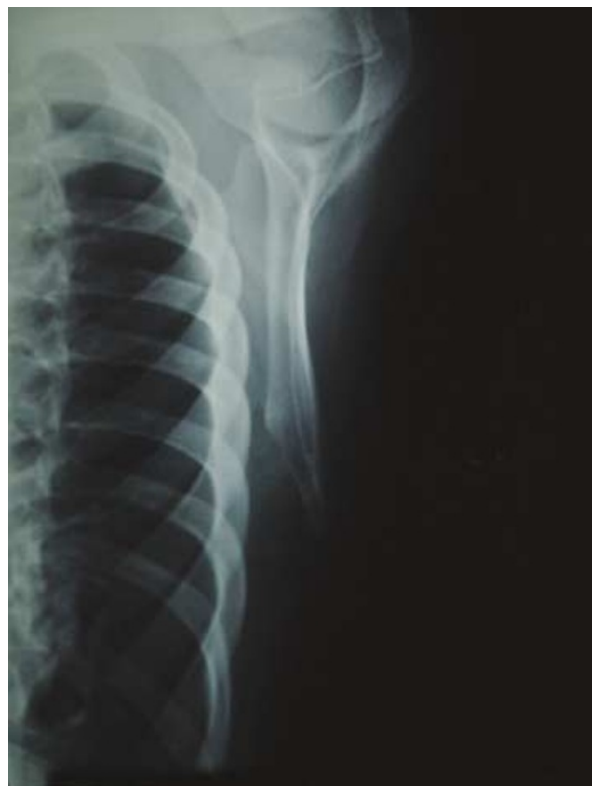

Fig. 4 Radiograph 6 months after surgery shows the absence of the exostosis and no recurrence 
Histological examination was carried out by an anatomical pathologist immediately after operation. The examined section showed zonation with a cartilage cap surrouding the periphery, enchondrial calcification, ossification in the middle and fully developed mature trabeculae in the center (Fig. 3).

During the first medical examination, the day after the surgery, the patient reported the disappearance of the previous painful symptoms, and during the next fifteen days he obtained complete use of the shoulder. In subsequent medical examinations, no pain or reccurrence was noted. A radiographic examination performed after six months showed the absence of reccurrence in the same place (Fig. 4).

\section{Discussion}

Clinical manifestation of osteochondroma in the scapula is strictly correlated to its size and location. It may manifest as a consequence of functional disorders caused by compression or by the impediment of movement of the overlying tendinous structures, which causes friction and subsequently the reactive bursitis that is the basis for the painful symptoms often involved.
Maheshwari et al. [8] described aspecific symptoms in a case of an extraskeletal para-articular osteochondroma of the knee. Inoue et al. [9] described a snapping phenomenon during adduction and internal rotation of the hip in a case of osteochondroma of the proximal femur [9].

The localization in the higher, lower and along the medial borders of the scapula may appear early, because of the direct contact with the muscular tissue. Regarding the other regions of the scapula, the mass must be of a large size in order to interfere with the muscular and neurovascular structures. Cases in which scapula osteochondroma was accompanied by incomplete paralysis of the frontal compact muscle by compression of the long thoracic have also been described. In most cases though, as in this case, when the formation is of inadequate size, these complications do not occur $[10,11]$.

Treatment of scapular exostosis consists of surgical removal, which is useful in eliminating painful symptoms and avoids possible transformation of the neoformation. Early preventive resection is necessary to avoid the risk of transformation of the mass into a malignant chondrosarcoma, which happens in $1 \%$ of single formations and more in multiple formations of the hereditary type [12]. The age range in which this condition may occur is from 30 to 40 years [1].

\section{References}

1. Lichtenstein L (1977) Bone tumors, 5th edn. Mosby, St. Louis, pp 26-30

2. Campanacci M (1981) Esostosi solitaria ed esostosi multiple ereditarie. In: Aulo Gaggi (eds) Tumori delle ossa e delle parti molli. Bologna, pp 157-178

3. Murphey MD, Choi JJ, Kransdorf MJ et al (2000) Imaging of osteochondroma: variants and complications with radiologic-pathologic correlation. Radiographics 20:1407-1434

4. Gulati Y, Maheshwari A, Sharma V et al (2005) Extraskeletal osteochondroma of the thigh: a case report. Acta Orthop Belg 71:115-118
5. Dorfman HD, Czerniak B (1998) Osteochondroma. In: Bone tumors. Mosby, St. Louis, p 331

6. Mancini A, Morlacchi C (1995) Esostosi osteocartilaginea. In: Clinica Ortopedica, manuale atlante. Piccin, Padua, p 168

7. Melarkey DW, Roffinella JP, Kaplan H (1966) Osteocartilaginous exostosis (osteochondroma) of the mandibular condyle: report of case. J Oral Surg 24:271

8. Maheshwari AV, Jain AK, Dhammi IK (2006) Extraskeletal paraarticular osteochondroma of the knee, a case report and tumor overview. Knee $13: 411-414$
9. Inoue S, Noguchi Y, Mae T et al (2005) An external snapping hip caused by osteochondroma of the proximal femur. Mod Rheumatol 15:432-434

10. De Palma AF (1983) Tumors and tumorous conditions of the shoulder girdle. In: Surgery of the shoulder, 3rd edn. Lippincott, Philadelphia, pp 669-670

11. Milch H (1950) Partial scapulectomy for snapping of the scapula. J Bone Joint Surg Am 32:561-566

12. Merck Sharp \& Dohme (2006) Manuale Merck: Malattie muscolo scheletriche del tessuto connettivo 